\title{
On Becoming Educational Researchers: The Importance of Cogenerative Mentoring
}

Judi Harris

College of William and Mary

Tamara L. Freeman

Pamela W. Aerni

Follow this and additional works at: https://scholarworks.wm.edu/educationpubs

Part of the Education Commons

\section{Recommended Citation}

Harris, J. B., Freeman, T. L., \& Aerni, P. W. (2009). On becoming educational researchers: The importance of cogenerative mentoring. Mentoring \& Tutoring, 17(1), 23-29.

This Article is brought to you for free and open access by the School of Education at W\&M ScholarWorks. It has been accepted for inclusion in School of Education Articles by an authorized administrator of W\&M ScholarWorks. For more information, please contact scholarworks@wm.edu. 
Running head: COGENERATIVE MENTORING FOR EDUCATIONAL RESEARCHERS

On Becoming Educational Researchers: The Importance of Cogenerative Mentoring

\author{
Judith B. Harris \\ School of Education, College of William \& Mary \\ P.O. Box 8795 \\ Williamsburg, VA 23187-8795 \\ judi.harris@wm.edu
}

Tamara L. Freeman

tlfree@wm.edu

Pamela W. Aerni

pkaern@wm.edu

Published as:

Harris, J.B., Freeman, T.L., \& Aerni, P.W. (2009). On becoming educational researchers: The importance of cogenerative mentoring. Mentoring \& Tutoring, 17(1), 23 - 39. 


\begin{abstract}
The purpose of this reflexive action inquiry was to examine, from students' and instructor's differing perspectives, the authenticity (or lack thereof) of doctoral-level research methods instruction. The idea for this collaborative self-study emerged organically as a byproduct of a voluntary year-long research apprenticeship in which two of the authors were engaged, following coursework in both quantitative and qualitative research methods. The apprenticeship was facilitated by the third author, a faculty member and methods course instructor. The importance of cogenerative dialog as an organizing process for methodological mentoring emerged as a central finding when the three authors collaboratively examined the across-case themes common to their autobiographical statements about and reflections upon learning to "do research." The study's results show how and why cogenerative mentoring - as distinct from cogenerative work — goes beyond typical experiences in research methods courses, assistantships, and even dissertation work, and is therefore recommended for doctoral students in education.
\end{abstract}

Keywords: research methodology; doctoral students; mentoring; cogenerative dialogue 


\section{On Becoming Educational Researchers:}

The Importance of Cogenerative Mentoring

More than ever before, doctoral study in education is being scrutinized by its participants: professors and students. Summarizing a comprehensive examination of the current state of doctoral-level study in education in North America, researchers working with the Carnegie Initiative on the Doctorate called for sweeping and systemic changes, saying:

The problems of the education doctorate are not acute. To call them such would suggest that they are new and of potentially short duration. In fact, the problems are chronic and crippling. Unless we face these issues squarely and with purposeful action, schools of education risk becoming increasingly impotent in carrying out their primary missionsthe advancement of knowledge and the preparation of quality practitioners. (Shulman, Golde, Bueschel \& Garabedian, 2006, p. 25)

Persistent questions about the purposes of doctoral work have become more complicated and urgent as programs have begun to prepare doctoral graduates for a range of very different employment options. Such diversification in doctoral students' preparation can make it challenging to maintain rigor and depth in programs, especially when they are learning to conduct research. The nature and quality of students' research training in education is being critiqued in a large and growing literature (Johnsrud \& Banaria, 2004; Walker, Golde, Jones, Bueschel, \& Hutchings, 2008). Despite this attention, doctoral candidates continue to experience frustration and dissatisfaction with program-based preparation for designing and conducting research (e.g., Cotner, Intrator, Kelemen, \& Sato, 2000).

The purpose of this reflexive action inquiry (Tripp, 2003), therefore, was to examine, from students' and instructor's differing perspectives, the authenticity (or lack thereof) of 
doctoral-level research methods training. To what extent and in what ways was students' structured methodological learning experienced as "real research," and why? To what extent can this experience be "real," within the context of a doctoral program? The idea for the collaborative self-study through which we sought storied answers to these questions emerged organically as a byproduct of a voluntary year-long research apprenticeship in which two of the authors (Pam and Tamara) were engaged, following coursework in both quantitative and qualitative research methods. The apprenticeship was facilitated by the third author (Judi), a faculty member and methods course instructor.

When the three authors collaboratively examined the across-case themes common to their autobiographical statements about and reflections upon learning to "do research," the importance of cogenerative dialog emerged as a central finding. Cogenerative dialog is "radically democratic" discussion among collaborators with varying experience and expertise (Roth, Tobin, \& Zimmerman, 2001). Our results suggest that this form of interaction was what distinguished the methodological mentoring of the two student researchers. The sections that follow reflect each author's unique experiences, showing how and why "cogenerative mentoring" for doctoral students - that is, "radically democratic" communication and collaboration that acknowledges and accounts for differences in experience and expertise - goes beyond typical experiences in research methods courses, graduate research assistantships, and even dissertation guidance.

\section{Doctoral Students Becoming Researchers}

The exploration of research methodology is as much an academic socialization process as it is a conscious focus for doctoral-level study. Becoming a researcher requires building somewhat indeterminate knowledge that most practitioners argue is best developed by working alongside experienced researchers (Delamont, Atkinson, \& Parry, 2000) — in particular, the 
dissertation mentor (Leahey, 2006). Roth and his co-authors (1998; 2003) have depicted this process as an example of what Lave and Wenger (1991) describe as true legitimate peripheral participation.

The term legitimate peripheral participation refers to a way of understanding learning that explicitly acknowledges the dialectical relation of individual subjects and the collective in which they are a part; learning can be best regarded as changing participation in these settings rather than passively absorbing and processing information presented to them. (Lee \& Roth, 2003, Legitimate peripheral participation: in theory section, para. 1)

As such, doctoral students' learning to do research is always social and a legitimate contribution to their communities of practice. At the same time, it is differentiated from the participation of more experienced researchers in the community, yet it both results from and contributes to distributed cognition involving more senior colleagues. Lave and Wenger (1991) remind us that "newcomers' legitimate peripherality...crucially involves participation as a way of learning — of both absorbing and being absorbed in — the 'culture of practice.'" (p. 95) Hence, it would seem that doctoral students learn to do research primarily by doing research, albeit in a legitimately peripheral way, gradually and over time.

Lee and Roth (2003) note that learning to do research in a community of practice is a matter of "becoming and belonging;" processes that are "not necessarily easy." (Struggles section, para. 1) Lave and Wenger (1991) acknowledge simultaneous and conflicting experiences of power and powerlessness for legitimately peripheral participants that may explain some of the difficulties doctoral students encounter:

...legitimate peripherality is a complex notion, implicated in social structures involving relations of power. As a place in which one moves toward more-intensive participation, 
peripherality is an empowering position. As a place in which one is kept from

participating more fully - often legitimately, from the broader perspective of society at large - it is a disempowering position. (p. 36)

In learning to be researchers, rather than just learning about research methods, doctoral students' professional identities change as they begin to participate more actively in unfamiliar communities of practice. Lave and Wenger (1991) call the byproduct of this shift a "continuitydisplacement contradiction," which emerges due to "the different ways in which [community] old-timers and newcomers establish and maintain identities" (p. 115). Such differing notions of self — and therefore differing views and preferred courses of action relative to practice — are rooted in the inherently different roles played by more and less experienced members of the same community. These differences inevitably cause conflict. It is through the tension, however, that the student moves gradually from the periphery of a research community of practice toward its core, gaining methodological experience and expertise along the way.

\section{Mentoring Researchers}

Recently, researchers have begun to question whether this struggle is necessary, especially for women doctoral students, for whom existing models of autonomy developed through comparatively independent, competitive struggle can conflict with prior socialization, evoking strong and counterproductive emotional reactions to doctoral-level study. Lee and Williams (1999), for example, argue that for many women, "the pedagogy which produces the autonomous subject is often fraught and unsatisfactory, and is often experienced in terms of neglect, abandonment, and indifference on the part of the supervisee." (p. 17) Successful mentoring for doctoral students is now seen to be built upon interaction, community, a sense of belonging, and student agency (Bean, Readence, Barone, \& Sylvester, 2004). 
Stansell (1997) suggests that mentors often create these supportive conditions unconsciously, and by modeling. Much of the success of the mentoring experience may rest upon the mutuality and authenticity of the mentor-protégé relationship. The extent to which a protégé feels that the "mentor values [her] thoughts, ideas, and perspectives" and the "depth of [her] connection with the mentor" (p. 126) determines whether the mentor's advice is heeded. Stansell therefore recommends a "climate of mutual mentoring," "when conditions are created for students to be powerful in their own right and to claim their own expertise." In this climate, Stansell, says, "everyone is both teacher and learner." (p. 141) This, he asserts, is "transactional, rather than interactional:"

The individual circles of one become linked, part of a new and larger circle, rather than just caroming off each other, affected but essentially unchanged. Framing the mentoring relationship in transactional terms also echoes a phenomenon of mutualism. When organisms such as an alga and a fungus grow together for mutual support, they form a new organism, a lichen, which differs from both original organisms. And since mentoring relationships are often established across lines of power and status...it is when those relationships become mutualistic and transactional that the lines delineating our places in the hierarchy, as well as the hierarchy itself, can be called into question. (p. 142) Mullen (1997) sees this transition in the mentoring of doctoral students as one from "sharkdom and its dimensions of competition, exploitation, and abandonment, to post-sharkdom" — a new academic world in which mentors and protégés "might share leadership and tasks as well as dreams, fears, and truths." She recommends self-study collaborative projects such as the one described here, "taken on by those who value joint human effort and the revitalization of life 
in academe." (p. 151) We have come to see such collaboration as distinctively cogenerative in nature, and as essential to the development of methodological expertise.

\section{Cogenerative Dialogue}

Lee and Roth (2003) build upon earlier work about co-teaching as a collaborative research strategy (Roth, Tobin, \& Zimmerman, 2001) when they recommend cogenerative dialogue as a basis for mentoring doctoral students in research methodology. Eldon and Levine (1991) originated the notion of cogenerative learning as the primary mechanism for successful action research. Cogenerative dialogue is a radically democratic form of collaborative learning that depends upon mutual respect, rapport, inclusion of all stakeholders (regardless of differing expertise), and a multiplicity of participation opportunities for all (Roth, et al., 2001).

Cogenerative discussions embrace conflicting perceptions and opinions dialectically. Ross and his colleagues assert that it is only through such authentic participation that doctoral students truly become core members of research communities of practice.

Our inquiry has pointed to the necessity of cogenerative collaboration in doctoral students' authentic learning about research methodology. This learning goes beyond typical research design and data generation/analysis experiences. It requires the traditional doctoral mentoring relationship to become a more cogenerative endeavor.

\section{Mode of Inquiry}

This inquiry began as a post-meeting conversation one afternoon about learning to do research in anticipation of dissertation work. The three authors had been engaged in a year-long evaluation study of an educational technology project in another state, which they had planned and executed together. In the midst of learning to accommodate unforeseen (but quite usual) delays in survey data generation, the two doctoral students (Tamara and Pam) began to comment 
on how different this research experience was from all of their earlier experiences, both in courses and in other program-related activities.

When the instructor (Judi) saw how intrigued the students were with this topic, she asked them to think about whether they would like to systematically study their memories and impressions of learning to do research in multiple contexts. They enthusiastically agreed to write their experiences, reflections, and opinions in ongoing reflexive documents. These documents were shared at subsequent research meetings, during which the three participant-authors discussed the similarities and differences among the contents of their three documents in depth. After each of these meetings, the researchers continued to journal their experiences and impressions in response to the patterns identified. When the contents of the journals were shared and compared, the researchers' notes also recorded the themes that emerged as the authors continued to inquire, both individually and collectively, through discussion and writing, about authentic learning in becoming a researcher.

The three reflexive, autobiographical statements about learning to do or teaching others to do research, plus author-participants' notes and written digests of the content of the face-toface discussions, together comprise the data sources used for this inquiry. The researchers met once or twice monthly for several hours each time over the course of 13 months. The study's results are cogenerative in both content and process: from the emergence of the initial idea for the inquiry, through methodological planning, data generation/analysis, and creation of the final multiple-voiced document. We used our collaborative inquiry to help us to understand in microcosm what is and is not effective in assisting doctoral students' growth as researchers. 


\section{Results}

We begin our presentation of the results of this inquiry with historical statements from each of the two doctoral students, in which they report and interpret their experiences in learning to do research. We then make note of the similarities and differences between these two sets of experiences and perceptions, adding their mentor's response. Then, considering these three perspectives together, we offer collaboratively constructed notions of cogenerative mentoring, along with recommendations for implementation.

\section{Tamara: Authentic Learning?}

As a certified speech/language pathologist and a Ph.D. candidate in Special Education Administration, I have been a student in one form or fashion for most of my life. I suspect that I have been a research apprentice, honing my skills within informal and unplanned contexts that have arisen throughout my life. It seems as if I have always sought in-depth explanations for everything that I have observed or encountered, from relationships to life-defining events. Reflecting on my evolution as a budding educational researcher, I realize that my course has been haphazard at best.

I was presented with my first opportunities to research in authentic contexts during my senior year as an undergraduate. In a sociology class, four colleagues and I conducted interviews to gain insights about the social phenomenon of homelessness and reported the results in a culminating paper. The following semester I completed a senior thesis in which I used a public relations theory to analyze the demise of a proposed congressional mandate.

These academic experiences gave me my first taste of complete ownership of a research project, as well as a sense of accomplishment when they were complete. Although a large part of my motivation to successfully complete these projects stemmed from my desire to 
earn a good grade, my dedication ran deeper. As I engaged in both projects I began to really enjoy the process of collecting and analyzing data from a variety of sources. I had no idea that there was a name for what I was doing: triangulation. I just knew that I enjoyed the process of compiling the information and making sense of it. I found myself wanting to learn more about these types of projects.

At the time I did not know that I had been knee-deep in the messiness of research. However, when I began the research core of my doctoral program I realized that my sociology project could be best described as an ethnography. Moreover, I compiled most of the data for my senior thesis through a critical literature review. In hindsight, I realize that my sociology project was situated within an interpretivist research paradigm. Conversely, my senior thesis required me to operate within a positivistic paradigm.

While in my master's program, another graduate student and I helped a professor investigate the efficacy of a study skills class designed for at-risk students. We analyzed student data to determine the immediate and long-term effects of the class on the students' academic success. Although my colleague and I had a very positive rapport with Dr. E on a personal level, I did not feel as if we were equal participants in the project. Reflecting back on this experience, I believe that Dr. E enlisted our help not to train us as future researchers, but to meet her need to have many documents analyzed. We were not clear on the overall goals of the project or how our work fit into the overall project plan. This lack of clarity added to my uneasiness, as I felt unprepared and ill-equipped when we presented the project's findings at a national conference later that year.

Instead of feeling empowered by a strong sense of ownership, I felt that I was merely helping Dr. E out with her project. Additionally, we were left to our own devices to come up 
with an organizational system to classify the students and analyze each document in an objective and consistent manner. As I have learned more about reliability and validity issues related to research, I question whether this project yielded quality work. I can best describe this aspect of my research experience as "the blind leading the blind."

In hindsight, I am particularly troubled by this experience because neither my colleague nor I had sufficient knowledge of research methods to be given so little direction. The required research course that we had taken provided a cursory overview of research methods. Our unaided actions were based on our best judgments instead of well-informed research design. Perhaps this research experience would not have been so disconcerting had Dr. E provided clear directions and support. At times there is something to be said for "trial-by-fire" experience. Perhaps this not-so-positive experience had the unexpected consequence of piquing my interest in conducting quality research.

To complete my master's work, I was required to do a research project. During this process, I worked with my advisor to identify an area of research interest, constructed research questions and conducted a field-based experiment. Although my advisor was very supportive, she offered more feedback on the mechanics and format of writing the research paper than the implementation of the experiment. The project, while an authentic learning experience, was only an instructional tool used to orient us to the generic tasks involved in conducting research. Thus, this experience merely acquainted me with the research process and did very little to develop the knowledge and skills that I needed to be a true researcher.

Years have past since I conducted this research study. Yet as I think about issues relevant to my upcoming dissertation study, I find myself wondering if I crossed ethical boundaries as I identified potential participants for my graduate research project. In my experiment, I compared 
the information processing abilities of cognitively impaired stroke patients to that of their unimpaired counterparts. Although I gained access to them through a licensed speech-language pathologist, and I obtained both written and verbal consent from each participant, was it ethically sound for me to accept consent from cognitively impaired participants?

Regardless of what the circumstances were, I believe that a great opportunity for authentic learning was overlooked. The directives I received regarding professional ethics could have been made more salient had my advisor used Federal guidelines to frame our discussions. In fact, it would have been even more helpful if my advisor had required me to go through the process of obtaining human subjects approval before conducting my experiment. The lack of attention given to research design compromised the authenticity of the project. I created and disseminated a survey to be completed as part of the data collection process. It was not until I began my doctoral work that I was introduced to notions of instrument reliability and validity. At first I thought that my past experience with survey research was unique. However, when I hear my professors lament about students who plan to create and use untested instruments in their dissertations, I suspect that my past experience is similar to that of other doctoral students.

Still, the research project gave me an opportunity to collaborate with speech-language pathologists in the field to conduct an experiment. From this standpoint it offered an authentic experience, in that researchers often do their work collaboratively. In addition, organizing and writing a research paper reporting experiment results introduced me to what would be expected of me in my future as a researcher. Moreover, I had ownership of this project and was invested in seeing it through to the end. 


\section{Pam: Research Assistance?}

As an undergraduate student studying family and child development, most of my coursework focused on developing objective observation skills to ascertain when students achieved developmental milestones. My training in the assessment of child development started in a laboratory setting under the guidance of two professors, who taught me how to record anecdotal notes regarding students' behaviors and actions objectively. At the time, I wondered what their rationale was for me watching children and recording factual observations. How were these data related to individual student(s)' development?

In my preschool classroom, anecdotal notes detailed student progress, helping me to determine which students were on target as well as alerting me to areas in which students were not meeting benchmarks. With my elementary school students, I relied frequently on the observation skills that I developed as an undergraduate to clarify my understanding of students' individual needs and guide the development of lesson plans. I discovered that keeping anecdotal notes helped me to assess student progress without having to continually test students, making more time available for individual and group instruction.

As I worked on my master's degree in elementary education, I rediscovered the value of keeping detailed anecdotal notes, especially as they relate to qualitative research. I eventually realized that recording and analyzing notes daily regarding student progress in my classroom was an informal form of action research. I wondered if other classroom teachers realized they were conducting research every day. Armed with this new understanding, I eagerly delved into an educational research project required for a graduate course, wanting to learn how to effectively conduct action research in my classroom to foster better student outcomes. However, my enthusiasm dwindled when I began working on my master's thesis. 
For my thesis, I was required to design and carry out a small-scale replication of a prior research study. Minimal instructions had been provided in the course syllabus regarding how to begin the design process, so I sought out the advice of my advisor, as well as my educational research methods instructor. When I asked questions, my advisor referred me back to the guidelines, but offered little methodological assistance. My research methods professor referred me back to the textbook, which contained one small section on replication studies. Didn't he know that I had already consulted numerous resources before requesting his assistance?

Following the advice of my academic advisor, I completed the paperwork necessary for human subjects review, which included permission letters from the superintendents, building principals, parents and students who were directly involved in my research study. Later, I discovered that several of my fellow classmates did not meet this important requirement. This caused me to speculate whether course-related research projects are not only part of a learning process, but also a "test" that demands the resourceful, yet creative thinking of graduate students to pass

I wondered whether this was an initiation rite_or did my professors really believe that I possessed the skills needed to conduct a research study independently? Could they have felt that it was unethical to provide too much assistance? I was seeking a sounding board for my thoughts and ideas, as well as someone to help me to ensure that I was following protocols correctly. Though I successfully completed the small-scale study, I did so feeling as if I had been denied the opportunity to learn essential research skills under the guidance of an expert.

After completing my master's degree, I participated in a research study that focused on developing leadership teams in schools, like mine, interested in adopting an inclusive education model. My interest in conducting educational research was piqued during this experience. I 
collected data regarding student and teacher performance and participated in team discussions to analyze the data to create an action plan. This resulted in small, yet powerful changes in how the teachers provided instruction to diverse student populations. Participating in the research project left me with many questions regarding the strength of my own research knowledge. I decided to enter a doctoral program to enhance my current skills and develop new ones.

As a doctoral student, I assisted professors with their research projects, but in truth these assignments were merely data collection or data input tasks. One experience in particular was presented to me as an opportunity to work directly with a professor to gather and analyze data regarding issues of curriculum and instruction. Instead, my work on the study was limited to completing standardized observation forms, which I then scanned and prepared for analysis with a software program. When I inquired about the possibility of assisting with data analysis, the professor told me that "was the fun part," and that my assistance was not needed. I wondered what I had to do to prove myself worthy of genuine collaboration in all phases of research. Looking back, I wonder why some professors exclude graduate students in this way.

If doctoral students were provided opportunities to collaborate directly with professors on research projects, would roles and expectations change? Again, I questioned how I would ever develop effective data analysis skills if most of my experience with educational research focused upon data generation and collection. If doctoral students serve as research assistants to provide them with real-world experiences of knowledge generation, I question the rationale for not including us more actively in the analysis of data and reporting of results. Why would professors be reluctant to include graduate research assistants in all phases and processes of research? Is it fear? Is it uncertainty? 


\section{Pam and Tamara: Cogenerative Experiences}

Now, even though we have both completed our doctoral program coursework, we have had few opportunities to address the complexities of designing and implementing research studies authentically. One notable exception was presented in the qualitative methods course that we were required to take. By completing a small-scale phenomenological research study, the culminating project for the course, we experienced the collegiality that can characterize professional collaboration on research studies. Additionally, we noted our professor's willingness to cooperate with us by providing constructive feedback, encouragement, and support. However, the traditional roles of students and teacher continued to shape our interactions with the professor. Furthermore, because our projects partially fulfilled class requirements, our experiences were still somewhat contrived.

By discussing, comparing and reflecting upon our methodological histories, we have discovered that our experiences with learning to do research were markedly different until we became research apprentices. Although we traveled distinct paths previously, it was through these experiences that we were both prepared for our research apprenticeships. The mentoring relationship that evolved from our cogenerative work with Judi seemed to be the logical next step in our journeys to become skilled educational researchers.

\section{Tamara}

As a research apprentice, I enjoyed a more authentic experience, working with real data that had real ramifications. I no longer felt as if I were learning in a classroom. Instead, I perceived our interaction to be that of three colleagues working on a research project with equal footing and equal ownership. Soon, I realized that this apprenticeship was unlike my past experiences with research. However, I did not immediately recognize its cogenerative nature. 
After a few months of survey instrument development, I noticed the distinctive characteristics of our working relationship. We were learning from our interactions with one another. Thus, we abandoned the conventional rules that establish the professor as teacher and student as learner. Each of us was both teacher and learner.

Pam

My collaborative work with Judi and Tamara consisted of discussions, dialogues, and brainstorms. Our work sessions were times for us to openly share our thoughts and ideas. This synergy allowed me to take ownership of the study and be invested in its outcomes. Like Tamara, it was during the survey development sessions that I realized that we were partners with Judi, rather than participants whose limited authority and input were dictated by the lead researcher. Because I was more invested, my learning was deeper and more authentic. I felt empowered to offer suggestions, critique survey items, and most importantly, ask questions that I would have never posed in a classroom. Certainly this type of learning is what is necessary for all novice researchers.

\section{Pam and Tamara: Across-Case Themes}

As the group reflected upon the similarities and differences between Pam and Tamara's experiences in learning to do research, we noted six predominant themes. These include: the important differences between learning research skills vs. learning to do research; a strong thirst for authentic methodological knowledge; learning to do research as a "trial by fire;" the differences inherent in learning to do research inside and outside research methods classes; the pivotal nature of student-professor and professor-student roles and relationships; and the differing senses of ownership that result from different expressions of each. The four themes that were most directly related to cogenerative mentoring are explored below. 
Learning Research Skills vs. Learning to Do Research

Reflecting upon our past experiences prompted us to distinguish between learning to do research in authentic contexts and learning to do skills related to research in isolation. Through our course requirements, we both honed our abilities to collect and analyze multiple types of data. The classroom setting, however, was not conducive to us developing these skill sets authentically—by conducting research outside class requirements. Even when we were working on "real" research projects with seasoned researchers, our past experiences still fell short of providing us with the opportunity to learn to do "real" research.

Pam. As a doctoral student, I looked forward to assisting professors on their projects to become a more effective educational researcher. Each experience in which I assisted with a project presented an opportunity to continue to hone my data collection skills. The missed opportunities to work with professors on data analysis and the determination of research findings, however, created a void in my learning. While I am confident in my abilities to collect valid and reliable data for my dissertation study, my confidence wanes as I plan for data analysis, as I am unable to draw from many previous experiences.

Tamara. Similar to Pam, in my past experience as a graduate assistant, my sole responsibility was data collection. Unlike Pam, I was invited to participate in presentation of research findings. However, I did not learn about all of the nuances associated with conducting research because I was not included in every phase of the research process. I did not have a clear sense of how my work was related to the larger research project. As such, my first exposure to "authentic" inquiry did not help me learn how to conduct good research. 
Our current work has been markedly different from our previous work with professors and their research. We continue to develop specific skills that are necessary for a researcher to have, while simultaneously learning how to conduct all phases of a research study.

\section{Trial by Fire}

Our work together during our research apprenticeship has been very structured and systematic. Each task has had a clear objective and was directly related to our research project. We moved at a pace and in a manner necessary to ensure that each member of the research team was an active participant at all times. Interestingly, while we immediately sensed the nontraditional tone of our current research experience, over time, we have also realized that the distinctive nature of our work with Judi is an important element missing from many of our previous encounters with research.

Pam. Learning to do educational research during my master's studies appeared to be more of a rite of passage than an authentic learning experience. Professors assisted me in negotiating the steps of conducting a small-scale research study by providing information related to my specific questions. The task as presented was to learn the steps of conducting a research study, rather than applying methodological knowledge to design and complete a small-scale study. As a result, I was unable to envision how knowing the steps translated into one's ability to conduct educational research independently.

Tamara. I received basic directions intended to guide my research work as a graduate assistant. My professor gave me the agency to use my best judgment in collecting and classifying data. Unfortunately, the lack of concrete support and guidance encouraged my feelings of frustration and isolation. I perceived my work to be disorganized, incoherent and characteristic of "trial-and-error" - an approach that reinforced my feelings of uneasiness. 
Learning to do research in class vs. outside class

Shortly after we began our work together during the apprenticeship, we realized that learning to do research within the confines of a classroom is noticeably different from learning to do research outside the classroom context. Our qualitative research methods course was unlike our other research methods courses in that we worked in small groups to select topics of inquiry, then design and conduct small-scale phenomenological studies. While this class provided us with the opportunity to conduct genuine research, receiving grades for our final products helped to shape our perceptions that research skills were developed in a "simulated authentic" context within a classroom setting, and were therefore not completely authentic.

Pam. As the research apprenticeship project occurred simultaneously with my participation in the small-scale study in my qualitative methods class, I was immediately struck by the differences between the two. While working on the small-scale study in the qualitative course, the professor provided constant feedback through interactive facilitation for members of my research group. In contrast, within the context of the research apprenticeship project, questions and issues were discussed openly in a cogenerative manner as they emerged, with each person articulating often differing perspectives.

Tamara. I did not experience the ambiguity with which Pam struggled. I believe that I did not because unlike Pam, I had taken the qualitative methods course before engaging in our research apprenticeship. I felt that my professor encouraged our questions and supported our learning in every way feasible; however, due to limited time and other class-related constraints, she was unable to provide the level of individual attention that many of us desired. It seemed that she struggled to cover the necessary content while responding to our wishes to learn more about specific aspects of qualitative research. 
Conversely, our work outside the classroom was a more authentic learning experience, as we were engaged in the real-world outcomes of our research apprenticeship project. Knowing that the results of our research would be used by others to make decisions regarding the effectiveness of a professional development program made us realize that we were conducting real-world research with real-world ramifications and consequences. This was quite different from demonstrating our learning related to educational research, as we might have been doing in a research methods course.

\section{Ownership: Tamara and Pam}

As we reflect upon our varied, yet similar experiences in learning to do educational research, we recognize that we have complete joint ownership of an educational research study for the first time. In our previous experiences, a sense of true ownership was present only when we conducted our own research related to a course assignment. When working with professors on their research projects, we felt as if we were just assisting them in completing a portion of a larger endeavor.

During our self-study, we have pondered why our sense of ownership differs in this respect. What was missing from our research assistantships that was present in our research apprenticeships? Through ongoing individual reflection and many conversations with one another, we are now aware that our sense of ownership is related directly to our feelings of dedication to a project, how authentic we perceive a project to be, and the extent to which we believe that we are making a worthwhile contribution to our fields of study by completing it. As evidenced by our current inquiry, when we are truly dedicated to a project, our level of commitment and initiative is very strong. By reflecting on our past experiences, we recognize 
that our dedication is lower when we do not experience a similar sense of complete involvement, and therefore true ownership.

\section{Judi: "Teaching Researchers"}

When first learning to do research — and when first teaching others to do the same-I assumed that my experiences were typical, as Pam and Tamara did. In both cases, I was wrong, and in both endeavors, the essential difference focused upon the cogenerative nature of the mentoring that I both received and-because I had been mentored in this way-provided.

Pam and Tamara's disjointed experiences with learning to do research before their cogenerative research apprenticeship, however, are similar to other doctoral students' experiences that I have observed. I am struck by the complexity of the task at hand. How can we assist more doctoral students who are novice researchers to do research authentically (apart from the dissertation) when the very nature of cogenerative work is its "radical democracy?" Is it possible for researchers with very different levels and amounts of experience to do research together in a cogenerative and authentic way? We are attempting to answer this question, among others, in our self-study.

Like many doctoral students in education, when I first entered my program at a large research university, I had thought about teaching after graduation, but not about doing research. I was curious about the process, and excited to be able eventually to represent teachers' voices in research results more respectfully and in more authentic, pragmatic ways than I thought had been done to date. My plans at first focused upon continuing to teach; helping others to generate new understanding, rather than being responsible for doing this on my own.

I began my doctoral work just a year after Lincoln and Guba's Naturalistic Inquiry (1985) was published, and one of my professors was their contemporary and colleague. I remember 
being amused at how passionate research methodologists seemed to become about matters of research paradigm and procedure, yet this was common at the time, since the mid-to-late 1980's were when the postmodern "paradigm wars" in educational research methodology were waged. From within this tumult, I began to understand that there were multiple, equally valid ways of conceptualizing, designing, and doing research, though each approach certainly has its strong supporters and opponents.

My study of research design and methods as a doctoral student was similar to many, in that I took classes and did projects. The projects in my qualitative research methods classes were small-scale studies. The feedback from my professors, and eventually from the much-less-kindly manuscript reviewers who read the manuscripts that I wanted to publish in refereed journals, taught me the most about how to design and do nonpositivistic research. The field was simply too new in the mid-1980's for any text or course to help my classmates and me learn to design qualitative research in an organized and comprehensive way. At the time, I had no idea how fortunate I was to have this authentic, holistic experience with nonpositivistic research design and execution.

I did not see my doctoral-level, class-based research projects to be any less authentic than the grant-funded, cogenerative research and development in which I became involved later in my doctoral program. It surprised and perplexed me when I learned from Tamara and Pam that the course setting itself has limited the perceived authenticity of their learning experience in such essential ways.

Perhaps my most important experience as a doctoral student in shaping me as a researcher and teacher of researchers was my work and relationship with my primary mentor in the study of educational technology. Glen — a brilliant, funny, self-described "social autistic" 
with a heart of gold - worked with each of his doctoral students as colleagues with expertise in areas other than his own. Having never been a classroom teacher or taken an education course, Glen made it clear that if we were to convince existing and future teachers to use educational technologies in their teaching, we needed to fully utilize his technological and our educational expertise collaboratively. All of our work together-teaching courses, developing educational software and other resources, researching technology integration strategies in local schools, and sharing our findings with other educational technologists-was done collaboratively. I had no idea how unusual this cogenerative doctoral-level learning was until much later in my work in higher education. Glen told me recently that he modeled his collegial mentoring style upon how his own doctoral mentor worked with his students, and I have continued this interpersonal tradition.

I wonder now whether my very different experience of the authenticity and ownership of research projects (compared to what Pam and Tamara describe) within and outside doctoral-level research methods courses — as both a doctoral student twenty years ago and now as a research methods professor-is based upon the cogenerative nature of my interactions with my doctoral mentor. Had I had a more traditional (i.e., student-Professor) relationship with Glen, I might have framed the authenticity of course-based research projects and collaborative work with professors quite differently. Certainly it would have been much more difficult for me to make the post-graduation transition to pursuing my own research agenda, had I not had authentic, cogenerative research and development experiences while I was first learning to do research.

As a professor of education, an instructor of qualitative research methods courses and doctoral advisor and chair, I now understand that my students' experiences are considerably different from mine two and three decades ago. Qualitative research has matured in 
methodological scholarship, acceptance, and exposure. Most doctoral programs require at least one qualitative methods course in the core research sequence. With this acceptance and widespread exposure, however, have come several serious challenges for doctoral students seeking to become researchers, especially at institutions other than doctoral comprehensives (Carnegie Foundation, 2006).

Perhaps it is my background as an elementary-level teacher-educated to be learnercentered and to make learning as authentic and active an experience as possible - that has most influenced how I now teach research methods courses and work with doctoral students on research projects. My classes rarely contain lectures, are planned according to present and past students' expressed and demonstrated learning needs, and consist primarily of "minds on" learning exercises that simulate the aspects of research design and execution that the students are reading about and encountering in project work. All of my research methods classes incorporate, if not focus upon, an authentic research project.

Perhaps it is this same "learner-centeredness" that makes cogenerative mentoring an obvious choice for me in assisting doctoral students learning to be researchers. Perhaps it is because I was mentored in a cogenerative way that, like my mentor before me, causes me to recreate the types of relationships in the academy that I experienced. As with learner-centered elementary-level instruction, the benefits to learners at the doctoral level are considerable, yet time, effort, and relational demands upon both instructors and students are equally significant. We will explore these considerations in the following sections.

\section{Cogenerative Mentoring Relationships}

As empowering and beneficial as they may be for doctoral students and professors, cogenerative mentoring experiences are decidedly time- and effort-intensive, and can be 
confusing at times to all who are involved. We suspect that it is the crossing of traditional boundaries and working within new relational realms that causes this confusion, especially as it is situated within larger circles of more traditional power relationships within the academy. The cogenerative relationship becomes an island of sorts, the conditions for which can be remote from other collegial and instructional relationships. Lave and Wenger's (1991) notions of the simultaneous and conflicting experiences of power and powerlessness of legitimately peripheral participants are not avoided by engaging in this new form of educational interaction, however. In some ways, the stark differences between cogenerative work and more traditional mentoring may make academic power conflicts more noticeable and therefore more perturbing.

In attempting to synthesize disparate literature across disciplines to define mentors and mentoring, Mertz (2004) points to ...largely unexamined assumptions about mentoring...[including] that the mentor is committed to the goal of the relationship (e.g., career advancement of the protégé) or, at least, the same goal as the protégé; and that mentoring...[is] ipso facto beneficial to both parties in the relationship; that each party benefits; that each values the benefits to be derived; and that each is willing and ready to perceive or realize such benefits. (p. 544) At first glance, it would seem that cogenerative mentoring is aligned with these assumptions of traditional mentoring relationships. While that is true to some extent, we also note that the "radically democratic" (Roth, Tobin, \& Zimmerman, 2001) nature of cogenerative dialogue strains against the power differential implicit in the mentor's traditional focus upon the development of the protégé via giving advice and modeling. If the cogenerative mentor is to participate in the relationship as a colleague, then at times, she will speak from the position of a 
"more senior" associate with greater experience and expertise. At other times, she will request collegial support and feedback on leveled ground.

This role-related fluctuation can be confusing, especially initially, to protégés who are used to more traditional mentoring practices, as Pam's analysis (above) demonstrated in particular. Once it is tasted, however, cogenerative mentoring may be strongly-if not exclusively_desired by doctoral students. Since the widespread use of this type of mentoring is improbable in many academic settings at present, experiencing it with a minority of mentors may be the inadvertent cause for additional frustration. Pam and Tamara, for example, reflected for several weeks during our group self-study meetings about their wishes for research methods classes to be more cogenerative in nature. They suggested that Judi be an active, contributing member of every research team in an introductory qualitative methods class, instead of guiding each team's planning and implementation of a research design with ongoing consultation and feedback. In the end, we decided that organized classes, by the nature of the inherently different roles that instructors and students must play according to even the most generative and collaborative of instructional models, could not be completely cogenerative.

In this realization, we discovered another, more powerful notion: cogenerative work is distinct from cogenerative mentoring. Though both employ cooperation and conscious facilitation of learning, the former is primarily collaborative, while the latter, though emergent, is primarily guided. In the former, power structures are eliminated; in the latter, they are renegotiated, but still exist, though at times their influence is muted. It is in this essential difference in roles and identities that we believe the source of the tension resides that Lave and Wenger described among community-of-practice members. Moreover, our individual and collaborative reflections have led us to realize that the tension exists both within each 
participating student and instructor, and also between them. Understanding the dynamics and ramifications of this essential tension is key to the success of cogenerative mentoring for doctoral students learning to be researchers.

Cogenerative mentoring and work exist upon a larger continuum of participation and peripherality within a community of practice — in this case, the practice of educational research - that extends from the most peripheral to the most core involvement. Each endeavor can be located at a different point upon the continuum, based in large part upon the nature of the community of practice-based roles (peripheral to core) and project-related relationships (collaborative to guided) among the project's participants. These roles and relationships usually correspond to amount of practice-related experience. Over time, and as their methodological learning helps them to become increasingly independent and interdependent educational researchers, doctoral students move from legitimate peripheral to core participation in educational research communities, especially if they choose to continue their research work after graduation.

During earlier stages of doctoral students' learning, cogenerative mentoring is more appropriate, while cogenerative work becomes increasingly possible (and desired) as researchers develop practice-based expertise within the community over time. When these learning trajectories are interrupted, tension increases, and frustration results. Tamara, for example, described earlier how she and a colleague were "thrown into" core research participation too quickly in being asked to analyze data unaided, then present study results at a conference without what she felt to be requisite guidance. Pam, on the other hand, felt "blocked" from anything but the most peripheral participation in an educational research community when she wanted to 
function at a level closer to the core, by being asked to generate and organize data without being permitted to participate in study design, data analysis, and determination of study results.

When examining power-related disruptions within the relationship between a universitybased research supervisor and a teacher-researcher doing action research in her classroom as her master's thesis, Taylor and Dawson (1997) concluded:

...It is important that equity not be confused with equality....Equality is inappropriate because the student and supervisor bring to their educative relationship different types of expertise grounded in the authority of their distinctly different experiences. The principle of equity, however, aims to create a mutually valuable interdependency that eschews relations of domination while fostering an educative relationship of co-participatory teaching and learning. (p. 17)

Cogenerative work is based upon equality in collaborators' relationships; cogenerative mentoring is based instead upon equity. When these types of endeavors are seen as points along a developmental trajectory between peripheral and core participation within a community of practice, cogenerative mentoring can function as a bridge to core participation within educational research communities. This, then, is why we recommend cogenerative mentoring experiences for all doctoral students who wish to become researchers. 


\section{References}

Bean, T. W., Readence, J. E., Barone, D. M., \& Sylvester, T. (2004). An interpretive study of doctoral mentoring in literacy. Mentoring and Tutoring, 12(3), 371 - 381.

The Carnegie Foundation for the Advancement of Teaching (2006). The Carnegie classification of institutions of higher education. Retrieved August 7, 2007 from http://www.carnegiefoundation.org/classifications/

Cotner, T., Intrator, S., Keleman, M., \& Sato, M. (2000, April). What graduate students say about their preparation for doing qualitative dissertations: A pilot study. Paper presented at the annual conference of the American Educational Research Association, New Orleans, LA. Retrieved August 7, 2007 from http://www.stanford.edu/group/QDA/00pilot.pdf

Delamont, S., Atkinson, P., \& Parry, O. (2000). The doctoral experience: Success and failure in graduate school. Philadelphia: Falmer Press.

Eldon, M., \& Levin, M. (1991). Cogenerative learning: Bringing participation into action research. In W. F. Whyte (Ed.), Participative action research (pp. 127 - 142). Newbury Park, CA: Sage Publications.

Johnsrud, L. K. \& Banaria, J. S. (2004). Doctoral education: National issues with "local" relevance. Educational Perspectives, 37(2), 20 - 27.

Lave, J., \& Wenger, E. (1991). Situated learning: Legitimate peripheral participation. Cambridge, England: Cambridge University Press.

Leahey, E. (2006). Transmitting tricks of the trade: Advisors and the development of research knowledge. Teaching Sociology, 34(2), 93 - 110. 
Lee, S. \& Roth, W. - M. (2003, May). Becoming and belonging: Learning qualitative research through legitimate peripheral participation. Forum Qualitative Sozialforschung/Forum: Qualitative Social Research, 4(2). Retrieved on August 7, 2007 from http://www.qualitative-research.net/fqs-texte/2-03/2-03leeroth-e.htm

Lee, A. \& Williams, C. (1999). 'Forged in fire': Narratives of trauma in Ph.D. supervision pedagogy. Southern Review, 32, 6 - 26.

Lincoln, Y. S., \& Guba, E. G. (1985). Naturalistic inquiry. Thousand Oaks, CA: Sage Publications.

Mertz, N. T. (2004). What's a mentor, anyway? Educational Administration Quarterly, 40(4), $541-560$.

Mullen, C.A. (1997). Post-sharkdom: An alternative form of mentoring for teacher educators. In M. D. Cox, C. K. Boettcher, \& D. S. Adoue (Eds.), Breaking the circle of one: Redefining mentorship in the lives and writings of educators (pp. 145 - 174). New York: Peter Lang Publishing, Inc.

Roth, W. - M., Lawless, D., \& Tobin, K. (2001). Time to teach: Towards a praxeology of teaching. Canadian Journal of Education, 25, 1-15.

Roth, W.-M., \& McGinn, M. K. (1998). Legitimate peripheral participation in the training of researchers in mathematics and science education. In J. A. Malone, B. Atweh, \& J. R. Northfield (Eds.), Research and supervision in mathematics and science education (pp. 215 - 230). Mahwah, NJ: Lawrence Erlbaum Associates.

Roth, W-M, Tobin, K., \& Zimmerman, A. (2001, April). Coteaching/Cogenerative dialoguing: Learning environments research as classroom praxis. Paper presented at the annual conference of the American Educational Research Association, Seattle, WA. Retrieved 
August 7, 2007, from

http://www.educ.uvic.ca/faculty/mroth/conferences/CONF2001/LER-AERA.pdf

Shulman, L. S., Golde, C. M., Bueschel, A. C., \& Garabedian, K. J. (2006). Reclaiming education's doctorates: A critique and a proposal. Educational Researcher, 35(3), 25 32.

Stansell, J. C. (1997). Mentors and mentoring: Reflections of a circle with/in circles. In M. D. Cox, C. K. Boettcher, \& D. S. Adoue (Eds.), Breaking the circle of one: Redefining mentorship in the lives and writings of educators (pp. 121 - 144). New York: Peter Lang Publishing, Inc.

Taylor, P. D. \& Dawson, V (1997, March). Critical research supervision? Deconstructing a disempowering myth. Paper presented at the annual conference of the American Educational Research Association, Chicago, IL. Retrieved August 7, 2007, from http://www.eric.ed.gov/ERICWebPortal/custom/portlets/recordDetails/detailmini.jsp?_nf pb=true\&_\&ERICExtSearch_SearchValue_0=ED411275\&ERICExtSearch_SearchType _0=eric_accno\&accno=ED411275

Tripp, D. (2003). Action inquiry (Action Research e-Reports 017). Sydney, Australia: Author. Retrieved August 7, 2007 from http://www2.fhs.usyd.edu.au/arow/o/m01/rtripp.htm\#Action\%20Inquiry

Walker, G. E., Golde, C. M., Jones, L., Bueschel, A. C., \& Hutchings, P. (2008). The formation of scholars: Rethinking doctoral education for the twenty-first century. Stanford, CA: Jossey-Bass. 